\title{
St John's wort was not better than placebo for reducing symptoms in major depressive disorder
}

\author{
Hypericum Depression Trial Study Group. Effect of Hypericum perforatum (St John's wort) in major depressive disorder. A \\ randomised controlled trial. JAMA 2002 Apr 10;287:1807-14.
}

\section{QUESTION: In patients with major depressive disorder (MDD), is Hypericum perforatum (St John's wort [SJW]) effective and safe?}

\section{Design}

Randomised (allocation concealed*), blinded (participants, clinicians, data collectors, outcome assessors, data analysts)*, controlled trial with 8 weeks of follow up plus a continuation phase for 18 weeks.

\section{Setting}

12 academic or community clinics in the US.

\section{Patients}

340 outpatients who were $\geq 18$ years of age (mean age $42 \mathrm{y}, 66 \%$ women); had a current diagnosis of MDD; and scored $\geq 20$ on the Hamilton Depression Rating Scale (HDRS) (mean score 22.8) and $\leq 60$ on the Global Assessment of Functioning (mean score 53.6) after a 1 week placebo run in period. Exclusion criteria included a score $>2$ on the HDRS suicide item, serious physical or psychiatric disorders, use of psychoactive drugs, and pregnancy. Follow up was $99 \%$.

\section{Intervention}

Patients were allocated to 1 of 3 groups: SJW, 900 $\mathrm{mg} /$ day of $0.12-0.28 \%$ hypericin $(\mathrm{n}=113)$; sertraline, 50 $\mathrm{mg} /$ day $(\mathrm{n}=111)$; or placebo $(\mathrm{n}=116)$. The main highest daily doses were $1299 \mathrm{mg}$ for SJW and $75 \mathrm{mg}$ for sertraline during the first 8 weeks; after 8 weeks, the respective mean highest daily doses were $1382 \mathrm{mg}$ and $89 \mathrm{mg}$.

\section{Main outcome measures}

Change from baseline HDRS score and full response (Clinical Global Impressions-Improvement [CGI-I] score of 1 or 2 and HDRS score $\leq 8$ ) at week 8 . Secondary outcomes included CGI scores and relapse (HDRS score $\geq 20$ and CGI-Severity score $\geq 4$ on 2 consecutive visits) during the continuation phase.

\section{Main results}

Analysis was by intention to treat. SJW (mean score change -8.7) and sertraline (mean score change -10.5) were not better than placebo (mean score change -9.2) for change from baseline in HDRS scores or clinical response (table). SJW led to more anorgasmia $(\mathrm{p}=0.04)$, frequent urination $(\mathrm{p}=0.003)$, and swelling $(\mathrm{p}=0.02)$ than placebo (table). Sertraline led to more diarrhoea ( $38 \% v$ $19 \%, \mathrm{p}=0.003)$, nausea $(37 \%$ ข $21 \%, \mathrm{p}=0.02)$, anorgasmia $(32 \%$ v 14\%, $\mathrm{p}=0.002)$, and sweating (29\% v 12\%, $\mathrm{p}=0.003)$ than placebo. Sertraline was better than placebo for CGI-I score at 8 weeks (mean score $2.04 v$ 2.45, $\mathrm{p}=0.02$ ). 1 patient in the SJW group relapsed during the continuation phase.

\section{Conclusion}

In patients with major depressive disorder, Hypericum perforatum (St John's wort) was not better than placebo for reducing symptoms.

*See glossary.

Sources of funding: National Center for Complementary and Alternative Medicine and National Institute of Mental Health.

For correspondence: Dr JR T Davidson Duke University Medical Center,

Durham, NC, USA. jonathan.davidson@ duke.edu

St John's wort (SJW) and sertraline (sert) v placebo for major depressive disordert

\begin{tabular}{lllll}
$\begin{array}{l}\text { Outcomes at } \\
8 \text { weeks }\end{array}$ & Comparisons & Event rates & RBR (95\% CI) & NNH (CI) \\
Full response & SJW $v$ placebo & $24 \% v 32 \%$ & $25 \%(-14$ to 51$)$ & Not significant \\
\cline { 2 - 5 } & Sert $v$ placebo & $25 \% v 32 \%$ & $22 \%(-18$ to 49$)$ & Not significant \\
& & & RRI (CI) & \\
\hline \multirow{2}{*}{ Anorgasmia } & SJW $v$ placebo & $25 \% v 14 \%$ & $81 \%(5.1$ to 216$)$ & $9(5$ to 105$)$ \\
\hline Frequent urination & SJW $v$ placebo & $27 \% v 11 \%$ & $139 \%(34$ to 333$)$ & $7(4$ to 19$)$ \\
\hline Swelling & SJW $v$ placebo & $19 \% v 7.8 \%$ & $142 \%(18$ to 400$)$ & $10(5$ to 44$)$ \\
\hline
\end{tabular}

†RBR = relative benefit reduction. Other abbreviations defined in glossary; RBR, RRI, NNH, and $\mathrm{Cl}$ calculated from data in article.

\section{COMMENTARY}

Herbal remedies, especially old ones, are appealing. SJW has been widely used for depression. Previous studies have compared various SJW preparations with low doses of a standard antidepressant or have reported a large placebo effect. ${ }^{1}$ The study by the Hypericum Depression Trial Study Group was intended to address these problems.

The results appear inconclusive: neither treatment differed from placebo. However, sertraline was inadequately dosed at the mean maximum of $75 \mathrm{mg}$ /day (recommended dose $50-200 \mathrm{mg} / \mathrm{day})$. Yet it was better than placebo on the CGI, with many partial responders and few side effects, so a higher dose may have been effective. The inadequate use of sertraline in this otherwise well designed and conducted study is hard to understand. The SJW dose was generous, with no hint of a response over placebo. The robust placebo response, consistent with mild or transient depression, showed why placebo controlled studies are necessary in this field. ${ }^{2}$

SJW is generally well tolerated, but problems can include anorgasmia, serotonin syndrome, photosensitivity, and hair loss. ${ }^{3}{ }^{4}$ The active ingredient(s) may be hypericin, hyperforin, or something else. ${ }^{5} \mathrm{SJW}$ can induce cytochrome p450s, 2D6, and 3A4, potentially reducing concentrations of oral contraceptives, antineoplastic and antiretroviral agents, and other drugs. ${ }^{15}$ Yet, $74 \%$ of SJW users had not sought medical advice.

In conclusion, the best study of SJW to date found it no better than placebo. Its pharmacological effects and active ingredients are not established. It may have substantial pharmacokinetic interactions, yet is generally used without medical supervision. Its use may preclude or delay accurate diagnosis and more effective treatment. St John's wort may not be effective, but it is not innocuous.

Alan C Swann, MD University of Houston Texas Medical School Houston, Texas, USA

1 Bilia AR, Gallori S, Vincieri FF. St. John's wort and depression. Efficacy, safety and tolerability-an update. Life Sci 2002;70:3077-96.

Kupfer DJ, Frank E. Placebo in clinical trials for depression: complexity and necessity. JAMA 2002;287:1853-4.

Parker V, Wong AH, Boon HS, et al. Adverse reactions to St John's Wort. Can J Psychiatry 2001;46:77-9.

Beckman SE, Sommi RW, Switzer J. Consumer use of St. John's wort: a survey on effectiveness, safety, and tolerability. Pharmacotherapy 2000;20:568-74.

Barnes J, Anderson LA, Phillipson JD. St John's wort (Hypericum perforatum L): a review of its chemistry, pharmacology and clinical properties. J Pharm Pharmacol 2001;53:583-600. 